\title{
COLECCIONISMO Y MECENAZGO
}

\author{
Mercedes Basso
}

Directora de la Fundación Arte y Mecenazgo (Barcelona) 

El coleccionismo juega un papel fundamental en la historia del arte. La Fundación Arte y Mecenazgo, que promueve "la Caixa", se centra en el estímulo del coleccionismo como fuente de mecenazgo. La escena del arte ha vivido un intenso desarrollo en las últimas décadas, principalmente sustentado por las instituciones públicas. La figura del coleccionista privado ha sido en este tiempo poco conocida y valorada. Cuando el apoyo público a la cultura se ha visto ampliamente reducido, la figura del coleccionista y mecenas cobra protagonismo. Sobre el coleccionismo de arte en España y su interpretación como fuente de mecenazgo tratará este texto.

Isidro Fainé, presidente de la Fundación Bancaria "la Caixa", fue quien impulsó la creación de la Fundación Arte y Mecenazgo. Para encontrar el punto de partida del compromiso de "la Caixa" con la cultura nos remontamos al inicio de la entidad, aunque en las primeras décadas los esfuerzos de la caja de ahorros se centraron en acceso a la vivienda, ahorro, educación o sanidad. Fue con la recuperación de la democracia cuando se instauró un programa cultural estable que ha evolucionado y crecido considerablemente desde entonces.

Una de las primeras manifestaciones visibles de este interés fue la apertura en 1979 del centro cultural en Barcelona. La entidad cuenta hoy con siete centros CaixaForum. Respecto a la colección de arte contemporáneo internacional, tan solo recordar que se inició en 1985 y hoy, más de treinta años después, sigue activa y ha reunido más de 900 obras.

Tras consolidar la red de centros cuyo objetivo es acercar la cultura a la sociedad por medio de numerosos programas dirigidos a todos los públicos, con una permanente dedicación al arte contemporáneo, se estimó que nuestro compromiso y actividad cultural había alcanzado la madurez suficiente como para escalar en objetivos hacia la creación del patrimonio artístico nacional.

Con esta motivación y el apoyo de un grupo de relevantes coleccionistas y mecenas, nació la Fundación Arte y Mecenazgo, cuya misión es estimular y divulgar el coleccionismo de arte en España y fomentarlo como fuente de mecenazgo.

Nos mueve la firme convicción de que el coleccionista es la piedra angular de las principales colecciones públicas, por lo que creemos necesario otorgarle el reconocimiento y el impulso que merece su aportación.

Podríamos decir que interpretamos, en clave contemporánea, la intención original del mecenas, personalizada en la figura de Cayo Cilnio Mecenas, patricio etrusco del siglo I a.C. que protegió a jóvenes talentos de la poesía y amigo de destacados autores como Virgilio y Horacio, y la versión moderna del mecenazgo que se dio a partir del Renacimiento.

El sector del arte español ha realizado un largo e intenso recorrido en las últimas décadas, alcanzando un grado de crecimiento sorprendente, especialmente a partir de la década de los 90, superando los límites de las principales ciudades hasta extenderse por todo el territorio. Nuestro país ha dado nombres de amplia proyección internacional, pero este corpus artístico y tejido cultural debe reforzarse y crecer, y para ello es necesaria la implicación de todos los que contribuimos a la creación y difusión de la cultura. Queremos señalar la necesidad de consolidar esta estructura.

Tradicionalmente dependiente del sector público, deberíamos ser capaces de encontrar una fórmula alternativa y plantearnos nuevos retos. La actuación debe encauzarse en diferentes sentidos: por un lado, el cambio cultural de relación público-privada para neutralizar miedos e interferencias y que resulte enriquecedor para ambos y, por otro, lograr cambios estructurales. 
Si hay coleccionismo hay más patrimonio, esta es una realidad ampliamente contrastada a lo largo de la historia.

Fortalecer y estimular el coleccionismo privado es deseable en un estado que ha alcanzado la normalidad en la difusión y disfrute del arte y la cultura en general, en una sociedad madura en la que la participación y la diversidad son ya una realidad. Pero los drásticos recortes han dejado los centros con apenas recursos para subsistir y para mantener activos los canales de producción. Habiendo desaparecido muchas vías de apoyo a la producción, este deseo se convierte en una necesidad.

Tras una primera fase centrada en el análisis de la realidad española del coleccionismo —básicamente a partir del rastreo público y entrevistas a los galeristas-, confirmamos que la intención de impulsar el coleccionismo era un desafío y que en nuestro país tan solo se había tratado el tema de manera puntual y en foros muy especializados. Las referencias eran escasas y su estudio inexistente. Esta frágil y desconocida realidad requería pues del esfuerzo para cambiarlo y del empeño en hacer pedagogía del coleccionismo. La sociedad debe tomar conciencia y asumir que coleccionar arte es generar riqueza para un país y, por tanto, dedicar los recursos necesarios en la tarea de conservar y enriquecer el patrimonio artístico debería ser una prioridad.

Por lo tanto, qué está a nuestro alcance para cambiar las cosas. Esa es la reflexión inicial.

El coleccionismo está poco desarrollado en España, la creación artística suele ser local, resulta difícil encontrar artistas españoles en el mercado internacional (que por el contrario es muy global), hay pocos profesionales que medien entre el artista y el coleccionista y muchas colecciones o patrimonio artístico son todavía inaccesibles, aunque se está produciendo un cambio de mentalidad. Por ello generar debate, crear referentes, fomentar su vocación pública y que se conozca facilitarán la legitimación de su valor social y contribuirán a normalizar el coleccionismo privado.

En este contexto, la fundación se orienta a la consecución de los siguientes objetivos:

- Promover la investigación desde la vertiente económico-cultural del coleccionismo y generar un corpus de conocimiento especializado y de referencia.

- Difundir los valores, la actividad, el significado de su aportación y modelos de excelencia del coleccionismo.

- Incentivar la participación privada en la difusión pública de la cultura.

- Conseguir reconocimiento público y privado para el papel de las colecciones privadas en la recuperación, la conservación y la creación del patrimonio artístico español.

- Promover cambios estructurales — legales, fiscales y de percepción de la actividad- que mejoren y faciliten la actividad de los agentes que participan en la conservación de patrimonio y la creación artística.

Para ello establecimos cuatro líneas de actuación, que son:

\section{Divulgación, promoción y reconocimiento del coleccionismo}

- Dar a conocer la aportación social que representa el coleccionismo de arte y difundir su labor.

- Propiciar la vocación pública del coleccionismo de modo que la ciudadanía tenga acceso a las colecciones a través de exposiciones, catálogos razonados, colaboración con museos y actividades culturales.

\section{Reflexión y debate}

- Acercar a nuestra escena del arte la experiencia y testimonio de especialistas de referencia en el ámbito internacional.

- Facilitar el intercambio de ideas entre coleccionistas y responsables de museos.

- Difundir y explorar nuevos modelos de colaboración entre los sectores privado y público.

\section{Observatorio del coleccionismo}

- Analizar el sector del arte en España para obtener conocimiento objetivo y fomentar su difusión.

- Organizar contenidos de referencia desde una perspectiva cultural y económica.

\section{Apoyo y representación}

- Apoyar los intereses de los coleccionistas e impulsar medidas para contribuir al desarrollo del coleccionismo.

- Proponer mejoras a la normativa vigente e impulsar la armonización de la legislación. 
Nos centramos en el coleccionista, qué le define, por qué es un mecenas, modelos de coleccionista, sus motivaciones y qué factores contribuyen al coleccionismo comprometido.

El coleccionista representa una parte esencial del sistema del arte porque permite al artista seguir creando y conserva nuestro patrimonio para el futuro. Es un eslabón fundamental de la cadena de valor que incluye al artista, al galerista, al crítico, al comisario, al conservador o al profesional de las subastas.

Ser coleccionista implica una responsabilidad, sin duda, porque están influyendo en la cultura. Las obras que se verán en el futuro serán las que se hayan coleccionado en cada generación.

¿Qué es coleccionar y quién es coleccionista? Manuel Fontán, director de exposiciones de la Fundación Juan March a quien citaré en varias ocasiones, define de este modo el acto de coleccionar:

En el fondo, el arte ha sido siempre aquello que se colecciona de acuerdo con determinados criterios. En sus orígenes, la obra de arte, en el sentido moderno de la palabra —el objeto que pertenece a la colección y cuya naturaleza consiste sola y exclusivamente en ser contemplado - comenzaba a serlo no tanto cuando salía de las manos del artista, como cuando era escogida para formar parte de una colección y entrar en el museo. Sin esa elección, las obras eran lo que han sido hasta que la moderna subjetividad las convirtió en arte: piezas que cumplían una función en los más diversos ámbitos de la vida religiosa, política y social (adornar y representar). Ser escogidas para ser valoradas exclusivamente por su belleza, ser elegidas como fines, ser salvadas del flujo temporal de lo útil, de lo que se usa, las constituía en obras de arte en sentido moderno. Y en eso consiste el acto de coleccionar. Lo que le confería valor artístico era la decisión de coleccionarlo, no su condición intrínseca. Coleccionar es en cada caso elegir determinadas cosas y dejar otras fuera.

Y la definición, según el coleccionista belga Heman Daled: «un coleccionista podría ser nada más que un par de ojos que ven lo que otros pensarán más tarde», «es una persona de acción, no habla, no es un crítico». 0, quizás, como opina de sí mismo, «estar algo loco».

También distingue entre construir o tener una colección. Y alguien que es coleccionista o que se convierte en coleccionista.

Para él un coleccionista 'es' y 'construye' y él se considera del segundo grupo, de los que se convierte en coleccionista y posee una colección. El coleccionista tiene una idea desde el principio y su ambición es que su colección sea lo más completa, compleja y ejemplar posible. Tienen una línea, un marco más o menos definido y que puede evolucionar pero la persona en cuestión es un coleccionista y quiere construir una colección.

En su caso nunca quiso construir una colección pero la tiene y por ello se convirtió en coleccionista. Es una evolución progresiva a medida que todo ocurre. Algo más parecido a recolectar o reunir aquello que se cruza en tu camino. "No he hecho una colección, solo he reunido lo que me interesó al cabo de los años» afirma. Considera su colección una muestra, un testigo. Hoy estas obras se han convertido en testigos de lo que ocurrió en un momento dado a un grupo de artistas que han alcanzado importancia histórica reconocida por el mundo entero.

En opinión del coleccionista Francisco Cantos, «te das cuenta que puedes considerarte un coleccionista de arte cuando vas a comprar una pieza aunque no tienes donde ponerla y sigues adelante y compras».

Y algo parecido recuerda el experto Michael Findlay en relación a unos de sus coleccionistas más admirados, un matrimonio que donó su colección al MoMA en 1967 sin condiciones, «el coleccionista es aquella persona que tiene que comprar cuadros tanto si puede permitírselo como si no».

Acabo de citar las razones que han llevado a seleccionar a 15 coleccionistas entre las 100 personas más influyentes del mundo del arte internacional, evidenciándose su condición de mecenas, porque el coleccionista es un mecenas.

Por supuesto en la relación comprador-obra de arte no siempre se da el componente de búsqueda lograda o deseo más propio del coleccionista pero nos interesa el coleccionista como mecenas. 
Son adquisiciones serias y responsables, que apoyan a los creadores, favorecen la producción y la conservación de patrimonio artístico.

Desde el punto de vista de Bartomeu Marí, ex director del MACBA, «El coleccionista se convierte en mecenas cuando comparte, cuando abre las puertas, cuando los criterios individuales, personales, confluyen con los ámbitos de calidad y significación que el experto, el historiador o el crítico aplican a la producción presente 0 pasada». El coleccionista también es, en cierto modo, un experto. Y vuelvo a citar al director de exposiciones de la Fundación Juan March, quien sitúa la mirada del coleccionista en un estadio anterior a la intervención de historiadores o críticos y dice: «A veces parece como si creyéramos que las obras de arte han existido siempre, han sido juzgadas y consideradas importantes por los críticos y los historiadores, que han configurado un cierto canon y entonces, en consecuencia, se las ha coleccionado».

Pero, en realidad, continúa Fontán, «el hecho de coleccionar es previo. Por ejemplo, es obvio que los museos y las colecciones han precedido a la crítica y a la historia del arte como disciplina profesional, que es una disciplina relativamente joven. Lo decisivo siempre ha sido decidir qué cosas se eligen para la colección y en consecuencia se conservan, y qué cosas se quedan fuera. Hay primero una especie de toma de decisión que determina lo que se va a contar después, porque, por definición, lo que se queda fuera nadie lo conoce ni puede por tanto contarse».

Es en ese gesto curatorial donde radica principalmente la responsabilidad del coleccionista. $Y$ en ese estadio del proceso, la calidad de las colecciones determinará la calidad de nuestro patrimonio futuro.

Francesca Thyssen, T-B A21 Thyssen Bornemisza Art Contemporary, de quien pudimos ver una selección de su colección en Gijón, comentaba «El papel del coleccionista tiene que ver con la filantropía. Con hacer posible la realización de obras».

Porque el coleccionista de arte contemporáneo se implica en la producción de obra de los artistas, como modo de coleccionar. Le motiva sentirse parte fundamental al posibilitar esa obra. En este rango de coleccionistas, por citar algunos, están Patrizia Sandretto, Han Nefkens, Carlos Rosón, Mario Legorburu o Sisita Soldevila.

La primera fase del proceso de una colección está centrada en estudiar, en mirar, conocer, investigar hasta que ciertas obras empiezan a inquietar y a llamar la atención. Cuando se inicia en la adquisición su faceta de mecenas empieza a materializarse. Los artistas dependen principalmente del interés de los coleccionistas. En muchos casos las obras quedan en el espacio privado del coleccionista pero, si este actúa con responsabilidad y vocación pública, sus obras serán conocidas por los especialistas, que podrán contar con ellas para exposiciones temporales u otros proyectos culturales. En esta relación las galerías que representan a los artistas también juegan un papel determinante como puente entre el ámbito privado y el público.

Tanto si se trata del conjunto de una colección o bien obras concretas, pueden atraer el interés de los museos, que deberían establecer desde el inicio del proceso de la colección fuertes lazos que lleven al coleccionista a evolucionar juntos o bien considerar que las obras puedan formar parte de la colección del museo bajo diferentes fórmulas que garantizarán su conservación, estudio y difusión. En algunos casos la colección es demasiado joven para un museo, en otros son obras de calidad acorde con el museo en cuestión.

Hay una pregunta muy interesante que plantear a los coleccionistas. ¿Qué piden o esperan del museo? ¿Cuáles son los factores que les atraen? ¿Qué retorno les motiva? Posiblemente se trate en la mayoría de los casos de un valor intangible asociado a la satisfacción por sentirse partícipes y haber visto reconocida su capacidad de elegir con criterio de experto.

Cuando nos referimos al coleccionista como mecenas deberíamos pensar en términos de complementariedad, de participación, de implicación, de hacer posible y de que se dé un enriquecimiento mutuo. Mientras suspiramos y nos alarmamos por la larga espera de la nueva Ley de Mecenazgo, debemos pensar en los aspectos positivos además del obvio de la financiación y dejar de pensar en parámetros de ley como solución. Porque el coleccionista no puede ni debe suplantar a las políticas públicas. 
¿Y cuáles son esas fórmulas de participación? ¿Cómo se gestan? ¿Cuándo empiezan?

Acercarse al museo local desde las estructuras que proporcionan por ejemplo las asociaciones de amigos y otras plataformas de conexión, se empieza ahí. Las instituciones responsables de la difusión del arte son las que van a formar el entramado necesario para promover el acceso del coleccionista y al coleccionista. Recuerdo cómo Patricia Phelps animaba a los coleccionistas a acercarse a los museos, pero también exigía de algún modo que los museos tendieran la mano a los coleccionistas.

Cuando hablamos de dar visibilidad a los coleccionistas como parte fundamental del reconocimiento, aparece cierto rechazo por parte de los responsables de museos, que ven en ello una vía de aumentar el valor de las colecciones o una interferencia en su programa.

Pero, tal y como señala Almine Ruiz Picasso, "A veces se observa cierto puritanismo entre lo privado y lo público, pero en mi opinión, si los papeles están bien definidos, estas contraposiciones carecen de base real».

O neutralizar esas reservas «haciendo exposiciones con colecciones y no de colecciones», como hace la Fundación Juan March. Seguro que el orgullo del coleccionista pasa por ver que sus obras significan una aportación al conocimiento, ofrecen al museo una posibilidad de crecer y llenan un hueco.

Plácido Arango: «No hay mayor satisfacción para un coleccionista que ver cómo el fruto de su labor sirve para enriquecer un museo público tan mágico e irrepetible como es el Museo del Prado. Me siento muy honrado al pensar que este grupo de obras principales reunidas a lo largo de mi vida vayan a encontrar su destino final en el Prado, museo al que me encuentro tan estrechamente vinculado como agradecido».

Deberíamos reflexionar sobre las razones que pueden llevar a un coleccionista a acercarse a un museo o un museo a un coleccionista e interiorizarlas. Improvisar radicalmente una relación que no ha existido antes resulta más que difícil pero «si los museos aplauden hoy sus adquisiciones y buscan más fórmulas para alentar pequeñas donaciones de jóvenes que quieren apoyar al museo, las donaciones serán el día de mañana mucho mayores» nos comentaba Leonard Lauder en su conferencia (disponible en www.fundacionarteymecenazgo.org).

En otros casos, ciertas fundaciones responden al tipo de institución precedida por el acercamiento a uno o más de los museos existentes, que intentan, pero no consiguen, prometer lo suficiente para satisfacer las aspiraciones del donante. Pero lleve o no el nombre del donante el museo privado, se trate de una donación a museos, con condiciones o sin ellas, toda esta filantropía cumple en último término una función social.

Ser coleccionista implica escoger un tipo de vida, es una dedicación exigente y plena que normalmente absorbe mucho espacio tanto vital como económico.

Me interesa revisar cuales pueden ser algunas de sus motivaciones y presentar algún modelo de coleccionista, evidentemente sin ánimo exhaustivo y lamentando no poder citar a todos los que dedican tantos esfuerzos a promover la cultura del coleccionismo.

He escogido la cita que abre el interesante libro de Michael Findaly El valor del arte y que, por cierto, recomiendo. En opinión de la muy activa coleccionista norteamericana Emily Hall Tremaine (fallecida en 1987): «Un coleccionista puede coleccionar por tres motivos: un sincero amor al arte, las posibilidades de inversión y la promesa social. Nunca he conocido a un coleccionista al que no le estimularan las tres cosas. Para que la satisfacción sea plena, la motivación dominante debe ser el amor al arte, pero dudaría de la integridad de cualquier coleccionista que niegue estar interesado en el valor que el mercado asigna a sus cuadros. El aspecto social es otra consideración que no tiene fin. De Roma a Tokio, nuestro interés nos ha proporcionado experiencias inesperadas e increíbles, y amigos tan llenos de vitalidad, imaginación y color como el arte que coleccionan».

Veamos algún caso lejano pero cuyos protagonistas no son millonarios, más bien al contrario. 
El matrimonio formado por Herb y Dorothy Vogel:

Herb (nacido en 1922) había estudiado historia del arte y fue empleado de correos en NY, y Dorothy (nacida en 1935) era bibliotecaria en Brooklyn. Se conocieron en 1960. Herb transmite a Dorothy su interés por el arte y, al poco de casarse, deciden vivir del sueldo de Dorothy y gastar el sueldo de Herb (ambos modestos) en comprar las piezas de arte que les gustaban. En 1991 los Vogel donan a la National Gallery de Washington, que habían visitado en su viaje de novios (hay una implicación emocional, marcó sus vidas), la colección de arte mínimal y conceptual que habían ido reuniendo en su diminuto apartamento. Son varios miles de piezas que convierten a aquel museo, el gran museo estatal americano, en un lugar de referencia para el estudio del arte desarrollado en Nueva York de las últimas décadas del siglo xx. Su colección de arte había ocupado casi todo el espacio físico de su apartamento, y también casi todo en sus vidas. Pero nunca la percibieron como un sacrificio o una obligación, ni tampoco como una inversión. Fue más bien una obsesión que vertebró su vida, que habla de quiénes son y de cómo son, de su determinación y de unos gustos muy personales, que definen un programa estético determinado, pero que habla también de su época y de su entorno cultural.

Un ejemplo actual y más cercano:

Han Nefkens, coleccionista holandés que reside en Barcelona. Su planteamiento es dejar sus obras en préstamo a museos europeos para los que su trabajo significa una ayuda. Solo compra cuando tiene una colaboración con un museo dispuesto a recibir en préstamo la obra. El reto es producir una pieza que de otra forma no hubiera existido. En realidad no son compras, son encargos para museos específicos.

Su colección gira en torno a la impronta de la fragilidad de la vida y su expresión es poética. En su caso, el valor social y artístico de la colección es compartido entre el coleccionista, el conservador y el director del museo.

Y, en Brasil, Bernardo Paz nos habla de su colección y de Inhotim, jardín botánico diseñado por Burle Marx «como el resultado de una preocupación social. Yo creo, dice, que cuando una persona es inteligente, es capaz de observar el arte contemporáneo y es capaz de entenderlo como arte político, como un arte direccionado, como un arte que critica y que muchas veces te dice lo que no debes hacer. La inteligencia está muy presente en el arte contemporáneo y es eso lo que diferencia el arte contemporáneo de todas las manifestaciones artísticas hasta hoy: es la perspectiva del futuro y la crítica del pasado».

Encarga obras grandes para ubicarlas en el enorme jardín botánico y estas deben contener una renovación del lenguaje, que sean un experimento y una vivencia para el espectador.

Coleccionar tiene en ellos una vocación social, por la necesidad de compartirlas para recrearlas de nuevo.

He citado antes a Daled, y daré de él una breve pincelada. Su colección de arte conceptual de los años 60 y 70 , que guardaba en su casa sin inventariar, fue expuesta en Múnich cuando Chris Dercon dirigía la Haus der Kunst. En ese tiempo fue visitada por los conservadores del MoMA, que vieron en ella la posibilidad de llenar el hueco del museo en los orígenes del arte conceptual y llegaron a un acuerdo para adquirirla. Estos objetos u obras de arte, que para él son objetos de conocimiento, le producen una profunda satisfacción.

El conde Panza di Biumo, de quien se vio parte de su colección en el Museo Reina Sofía en los años 80: «Comprender el arte nuevo tenía una importancia primordial para mí. [...] Era como descubrir una nueva teoría de la física o un nuevo cuerpo celeste. Nacía del mismo deseo, conocer lo desconocido».

Los auténticos coleccionistas no hacen sus elecciones tratando de anticiparse a la historia y al mercado del arte. Compran en sitios de confianza, gastan lo que pueden permitirse, y estas cantidades las consideran gastadas, no invertidas. A base de mirar constantemente, desarrollan un grado de conocimiento personal en su campo de interés, y están frecuentemente en contacto con otros coleccionistas, y con marchantes y conservadores que comparten su ilusión.

Y especialmente relevante es el caso que trataré a continuación.

La Fundación Juan March, premio al coleccionismo de la Fundación Arte y Mecenazgo en su edición de 2013, posee una colección que se expone permanentemente en sus dos sedes de Palma de Mallorca y de Cuenca. 
Además, en su actividad de investigación y producción de exposiciones temporales trabaja muy cerca de los coleccionistas privados. Concretamente, para La vanguardia aplicada, presentada en el 2012, participaron dos grandes coleccionistas, José María Lafuente y Merril Berman. Es muy recomendable la lectura del catálogo de la exposición, de cuyo texto-entrevista destacaré algunas ideas para dar cuenta del grado de complejidad y sofisticación al que puede llegar la motivación del coleccionista.

Para el coleccionista cántabro José María Lafuente, su interés por el arte empieza a través de una voluntad de saber muy autodidacta. Se forma con lecturas, va educando la mirada y luego pasa a otras realidades, empieza a hacerse preguntas en torno al arte contemporáneo. Quiere saber sobre las fuentes originales de lo que le interesa, y así llega a la documentación de vanguardia que no es simplemente arte, sino arte con una función: política, comercial, comunicativa...

Pero tanto Lafuente como Berman se dan cuenta de que no hay colecciones privadas dedicadas a ello y tampoco en los museos.

A Lafuente le preocupa la necesidad de escribir y contar esa historia paralela, a la que con el tiempo los museos han llegado a prestar más atención: la que transcurre a través de las ediciones, a través de las revistas, de los libros, de los soportes efímeros, en paralelo a esa historia del arte tan lineal, tan hecha de grandes nombres y grandes obras.

Para finalizar señalaré cuáles son en mi opinión los principales factores que estimulan el coleccionismo, cuantitativa y cualitativamente:

- La educación artística en las etapas de formación y en los museos.

- Un mercado del arte sólido, como medio para acceder a las obras y, por tanto, al contexto del coleccionismo.

- Las condiciones jurídicas y una fiscalidad adecuada para garantizar la conservación y generación de nuestra creación artística.

Debería procurarse la enseñanza del arte contemporáneo en las escuelas porque, además de dinero, para coleccionar es indispensable tener criterio y conocimiento. Ese interés por coleccionar dependerá de la historia cultural y de su arraigo en cada lugar.

El coleccionista mallorquín Joan Bonet no duda en considerar «que el coleccionismo que tenemos en España está en relación a la importancia y al interés que damos al arte. Si queremos potenciarlo debemos educar de otra manera a las nuevas generaciones y fomentar su estudio por medio de la enseñanza y de los museos»

La vía de la educación artística es, sin duda, el mejor incentivo para que los ciudadanos participen en el tejido cultural.

Considerar la educación como uno de los requisitos indispensables implica también la formación de los artistas pues es necesaria una educación especializada acompañada de movilidad, positiva tanto para su creatividad como para el acceso global de su obra.

Nadie comprará o iniciará una colección repentinamente, es una acción que requiere tiempo y aprendizaje, paciencia y sabiduría.

Y también en el ámbito de la educación podemos hablar de la formación a los coleccionistas desde la perspectiva de aportar información y conocimiento. Por supuesto nada más lejos que pretender FORMAR a un coleccionista pero sí buscar el modo de ofrecer aquello que normalmente no está al alcance por dificultad de acceso, inexistencia o dispersión.

Con el fin de incentivar el diálogo y la reflexión, la Fundación programa conferencias y encuentros para dar a conocer las experiencias de especialistas internacionales y debatir sobre nuevos modelos de actuación.

Bajo el nombre de Círculo Arte y Mecenazgo, en estas reuniones se abordan diversas y complejas claves del arte, poniendo énfasis en la aportación de las colecciones privadas a la difusión de la cultura. 
En el programa han participado:

Glenn D. Lowry, director del MoMA; Chris Dercon, director de la Tate Modern; Patricia Phelps de Cisneros, destacada coleccionista internacional fundadora de la Colección CPPC; Bernard Ruiz-Picasso, nieto mayor de Pablo Picasso y cofundador y copresidente de la Fundación Almine y Bernard Ruiz-Picasso para el Arte; Ginevra Elkann Agnelli, presidenta de la Pinacoteca Giovanni e Marella Agnelli; Patrizia Sandretto Re Rebaudengo, coleccionista y presidenta de la Fondazione Sandretto Re Rebaudengo; Clare McAndrew, fundadora y directora de Arts Economics; Leonard Lauder, presidente emérito de Estée Lauder Companies Inc y del Whitney Museum of American Art; Juan Antonio Pérez Simón, coleccionista y presidente de la Fundación JAPS; Lord David Linley, presidente de Christie's GB; Michael Findlay, director de Acquavella Galleries, NY; Alfred Pacquement, director del Museo Pompidou (2000-2013); Manuel Arango, empresario y filántropo; Philippe de Montebello, director durante 31 años del Metropolitan Museum of Art, Nueva York; Miguel Zugaza; Pierre Rosenberg, presidente director emérito del Musée du Louvre, y el coleccionista Eric de Rothschild.

El testimonio de nuestros ponentes ha sido reunido y editado para facilitar la experiencia de quienes tienen sólidas trayectorias relacionadas con el mecenazgo artístico. Cada conferencia ha sido transcrita, traducida y sintetizada para facilitar la reflexión sobre cómo debe establecerse la relación entre la sociedad y la difusión pública del arte. 